I wish to thank Dr. W. B. Jepson and Mr. R. J. Hussey of the Chemistry Department, University of Exeter, and Dr. J. E. Antill of the Metallurgy Division, Atomic Energy Research Establishment, Harwell, for providing the beryllium corrosion specimens. This work was carried out in the Crystallography Section of the Metallurgy Branch, Atomic Weapons Research Establishment, Aldermaston, under the direction of Dr. A. Moore.

\section{D. ScotT}

Atomic Weapons Research Establishment, Aldermaston, Berks.

${ }^{1}$ Mumro, W., and Williams, J., A.E.R.E. Report M/M108 (1956).

${ }^{2}$ Swanson, H. E., and Tatge, E., Nat. Bur. Stand. (U.S.A.), Cire, 539 1,36 .

${ }^{3}$ von Stackelberg, M., and Quatram, F., Z. phys. Chem., B, 27, 51 (1934).

${ }^{4}$ Kubaschewski, O., and Evans, F. Ll., "Metallurgical Thermochemistry"' (Pergamon Press, London, 1956).

\section{Photo-stimulated Emission of Exo-electrons from the Surface Layer of Amphoteric Metals reacting with Concentrated Sodium Hydroxide or Potassium Hydroxide}

WHILE studying the influence of liquids ${ }^{1}$ on the tribo-excited emission phenomena of exo-electrons (Kramer effect ${ }^{2}$ ) from metals, we have found that the amphoteric metals like aluminium, zine and tin as well as brass and some soldering alloys containing tin give a comparatively strong emission of exoelectrons when irradiated with visible light, after the freshiy abraded surface is sprayed with strong concentrated sodium hydroxide or potassium hydroxide.

Aluminium gives this strong emission even when the surface is not abraded.

This emission can also be measured from abraded cadmium. In this case, we think the emission is due to traces of zinc impurity in the cadmium.

The intensity of measured photo-stimulated emission decreases with the thickness of the covering layer of sodium hydroxide or potassium hydroxide. This seems to be due to the absorption of exoelectrons from the metal-solution interface region.

In darkness no significant emission is detected.

The preliminary measurements seem to show that each of the amphoteric metals has a different 'decay constant' for the emission from their reacting surface layers.

The emission was measured in atmospheric air with the aid of a point counter with a grid. The pulses in the counter could be completely suppressed by a retarding potential applied between the grid and the reacting metal $^{3}$.

The observed effect is not due to the exothermic character of the reactions. To prove it, the reactions of abraded zine and aluminium with concentrated hydrochloric acid have been examined using the same experimental conditions. In neither case was any photostimulated emission of exo-electrons observed.

The effect could not be observed for the metals iron, copper, bismuth, nickel, lead and magnesium when they were tested under the same experimental conditions.

Magnesium, which is known to give very intensive emission of exo-electrons under visible light after the abrasion of the surface (like aluminium) but which is known not to be amphoteric, shows a remarkable decrease of emission intensity after the emitting surface is sprayed with concentrated sodium hydrox- ide or potassium hydroxide. Aluminium, tin and zinc in contrast always show a strong increase under those conditions.

A detailed report will be published in Acta Physica Polonica.

Y. WAWRZYNIAK B. SUJAK*

Institute of Experimental Physics,

University of Wroctaw,

Wrocław, Poland.

March 23.

* On leave of absence at the Clarendon Laboratory, Oxford.

Lewowski, Tr and Sujak, B., Acta Phys, Pol. (in the press).

2 "Exoelektronentagung", Acta Phys. Austriaca, 10, 313 (1957).

${ }^{3}$ Sujak, B., Physikalische Blätter, 15, 209 (1959).

\section{Thin Films of Silver-Cadmium Alloy}

WE have undertaken a detailed electron diffraction study of thin films of silver-cadmium alloy obtained by evaporating the constituent metals consecutively in vacuum. Films of various compositions have been formed in this way and their phases and structures identified.

Near equi-atomic composition of this alloy system a crystallographic transformation has been reported by many workers employing $\mathrm{X}$-ray diffraction and other methods to occur in the bulk state ${ }^{1}$. By such studies it has been established that, in bulk state, the low-temperature $\beta^{1}$-phase (body-centred cubic ordered) structure changes to $\xi$-phase (closest-packed hexagonal) around $250^{\circ} \mathrm{C}$., although the exact transformation temperature is a matter of controversy. Employing high-ternperature electron diffraction technique, we have tried to investigate this transformation with the view of determining the exact transformation temperature in the case of thin alloy films. Careful and repeated observations with well-homogenized films about $500 \AA$. thick, giving a characteristic pattern of pure $\beta^{1}$-phase (body-centred cubic structure) at room-temperature, failed to reveal any change at all in the phase up to a temperature as high as $300^{\circ} \mathrm{C}$. The study could not be extended to higher temperatures because of the rapid volatilization of cadmium from the alloy films, leaving the films less rich in cadmium and consequently changing to $\alpha$-phase.

The details of the investigation will be published elsewhere.

\section{K. BAKADUR}

P. V. SASTRY

National Physical Laboratory,

Hillside Road, New Delhi, 12. March 19.

${ }^{1}$ Hansen, "Constitution of Binary Alloys", 13 (McGraw-Hill Book Co., Inc., Jondon, 1958).

\section{CHEMISTRY}

\section{Preparation of Tritiated Water Samples by Distillation}

IN many experiments using tritium as a tracer it is necessary to prepare a sample of pure water from organic material. During measurements of total body water using tritiated water in a dilution. technique we have obtained pure water samples from urine by distillation. The urine is placed in a small vessel (Fig. 1) the bulb of which is put in an oil-bath maintained at $110^{\circ} \mathrm{C}$. The distillate collects in the 